\title{
Osteochondroma of the Distal Tibia Leading to Deformity and Stress Fracture of the Fibula - A Case Report
}

\section{Chander Mohan Singh', Mohit Thapa Magar ${ }^{2}$ and Ajay Deep Sud ${ }^{1}$}

${ }^{1}$ Department of Orthopaedics, Armed Force Medical College, Pune, India

${ }^{2}$ Department of Orthopaedics, Nepalese Army Institute of Health Sciences, Shree Birendra Hospital, Chhauni, Kathmandu, Nepal

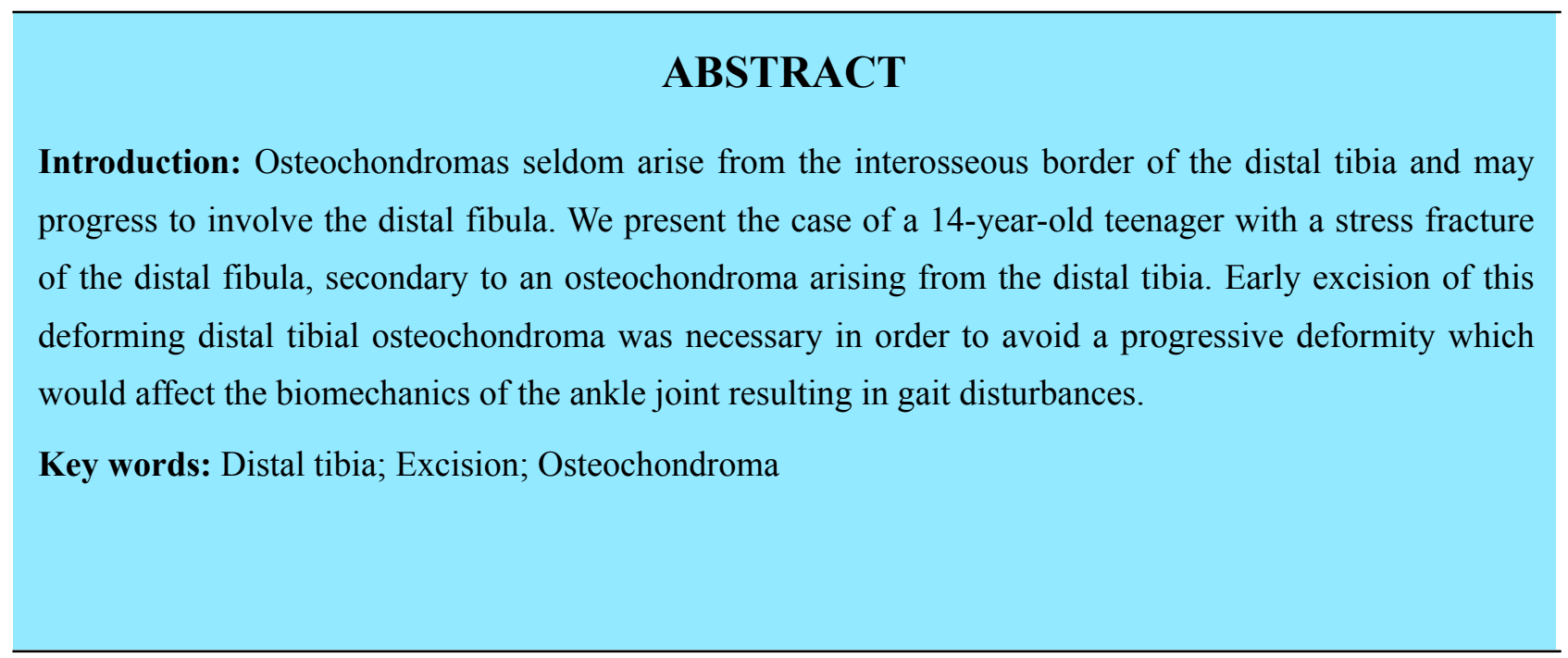

Correspondence: Mohit Thapa Magar, Department of Orthopaedics, Nepalese Army Institute of Health Sciences, Shree Birendra Hospital, Chhauni, Kathmandu, Nepal. E-mail: thapamagar@gmail.com

DOI: $10.3126 / \mathrm{mjsbh.v20i2.32856}$

Submitted on: $2020-11-12$

Accepted on: 2021-06-10 


\section{INTRODUCTION}

Osteochondroma or exostosis is a benign cartilaginous tumour of bone, derived from an aberrant sub-periosteal nest of the growth plate. It is the most common skeletal tumour, comprising $20 \%$ to $50 \%$ of benign bone tumours and $10 \%$ to $15 \%$ of all bone tumours. ${ }^{1}$ It may be solitary or multiple as in cases of multiple hereditary exostoses. The tumour consists of a well-defined bony outgrowth with thin outer cortices and an inner cancellous structure covered by a cartilage cap. It commonly occurs in the metaphysis of long bones and pelvis. The lesions may be pedunculated (with a stalk) or sessile (broad based). They are usually asymptomatic and are often discovered incidentally. Symptomatic lesions typically present in the second decade in consonance with the final growth spurt. Osteochondromas continue to grow till skeletal maturity and thereafter stop growing. ${ }^{2}$

The usual presentation includes the discovery of a painless mass which might be associated with activity related discomfort or pressure symptoms on a nearby neurovascular structure. Acute presentations could be due to fracture of a pedunculated lesion. We report a rare case of osteochondroma of distal tibia causing fracture and deformity of the distal fibula.

\section{CASE REPORT}

A 14 year old boy of lean built presented to us with history of progressively increasing swelling and deformity on the lateral aspect of right ankle for the last one year. He complained of pain around the ankle for the last three weeks, aggravated by prolonged walking or physical activity. There was

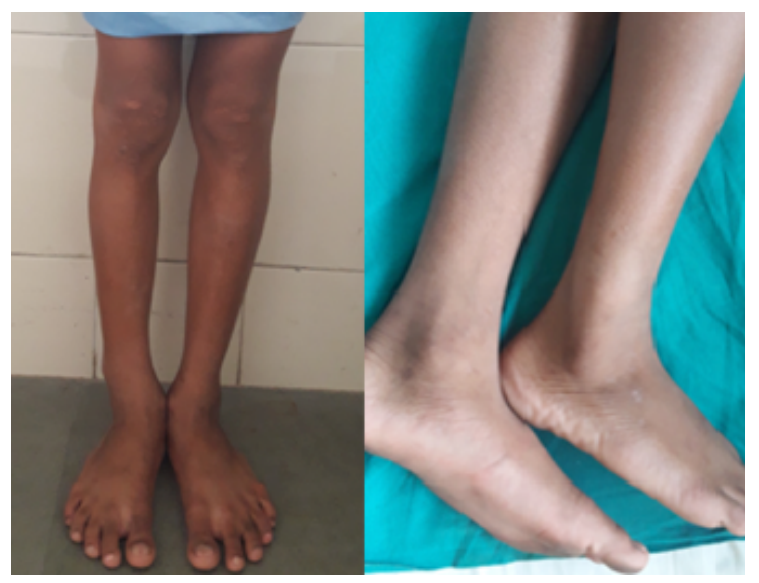

Figure 1. Varus deformity ankle with swelling no rest pain. On examination, there was a varus deformity at the ankle with a hard, globular swelling measuring $5 \mathrm{~cm} \times 3 \mathrm{~cm}$ over the anterolateral aspect of the ankle with a smooth surface and ill-defined margins as shown in Fig 1. The swelling was non-tender on palpation and there was no local rise of temperature. There were no distal neurovascular deficits and ankle range of motion was full and painless. The syndesmosis was intact clinically and there was no ankle instability. There were no similar swellings on the other extremities. The plain radiographs of the ankle revealed a welldefined, sessile, exophytic lesion arising from the interosseous border of distal tibial metaphysis with a clear zone between the lesion and the fibula suggestive of a cartilaginous cap consistent with osteochondroma. There was erosion, deformation and stress fracture of the fibula as shown in Figure 2.

Surgical treatment was opted for the patient in view of the patient's symptoms, fibular deformation with fracture, possibility of disease and deformity progression and a concern for future alterations of the ankle biomechanics. Through an anterolateral approach to the distal tibia, the lesion was exposed. It was sessile and covered by a cartilaginous cap which was irregular. The lesion was excised flush with the tibial cortex along with its overlying periosteum. The distal fibula had a fracture with breakage of the cortex resulting in abnormal mobility on examination at surgery. However, the ankle did not display any evidence of instability upon stress evaluation under image-intensifier guidance. This obviated the need for fixation of the fibula. Post-operatively, the patient was protected

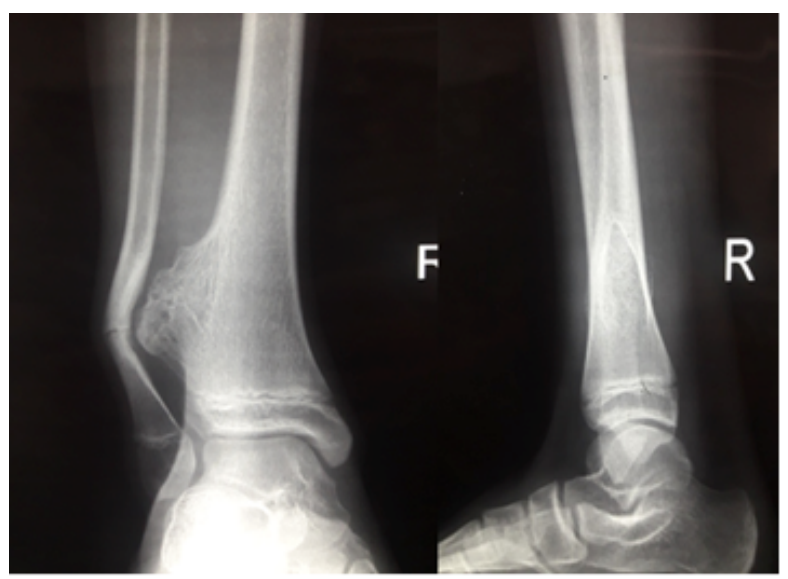

Figure 2. Radiograph Ankle AP and lateral view 


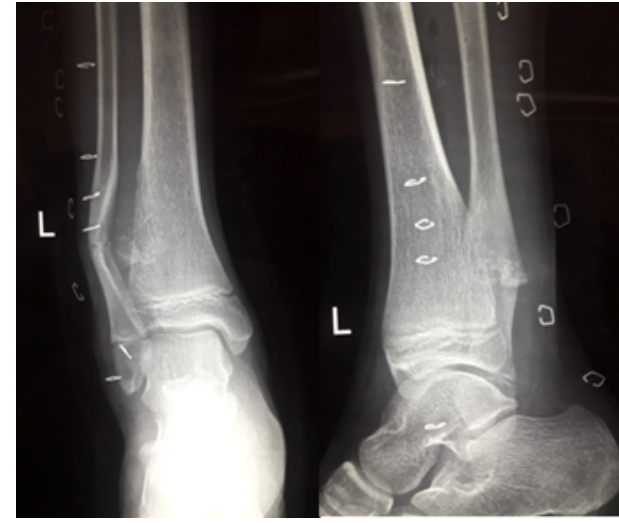

Figure 3. Post operative radiographs AP and lateral

and kept non-weight bearing in a below knee plaster for two weeks with progress to full weight bearing at four weeks. The post-operative radiograph showed a complete excision of the lesion as shown in figure 3. Histopathology of the excised specimen was consistent with an osteochondroma without any malignant transformation. Follow up was done at four and 12 weeks and at six months. At six months, the radiographs, as shown in figure 4, showed remodeling of the distal fibula with healed fibular fracture and a near complete clinical correction of varus. There was no evidence of any recurrence of the distal tibial lesion.

\section{DISCUSSION}

Osteochondroma, commonly known as an exostosis and often described as a benign bone tumour, is in fact a developmental anomaly rather than a true neoplasm. Disordered growth at the physis results in physeal growth perpendicular as well as the parallel to its long axis. Hereditary multiple exostoses are an autosomal dominant trait that presents with many osteochondromas. It tends to be diagnosed usually in the first decade of life itself, in almost $80 \%$ of afflictions. ${ }^{3}$

Solitary osteochondromas often go un-noticed and are likely to be discovered serendipitously or rarely when they cause symptoms due to pressure on adjacent neurovascular structures, deformities around joints and if they impede joint motion. As a result, their true incidence is possibly unknown. Pain is usually a result of fracture of a pedunculated lesion or rarely due to malignant transformation to chondrosarcoma (less than 1\%). Skeletal lesions that continue to grow after skeletal maturity or

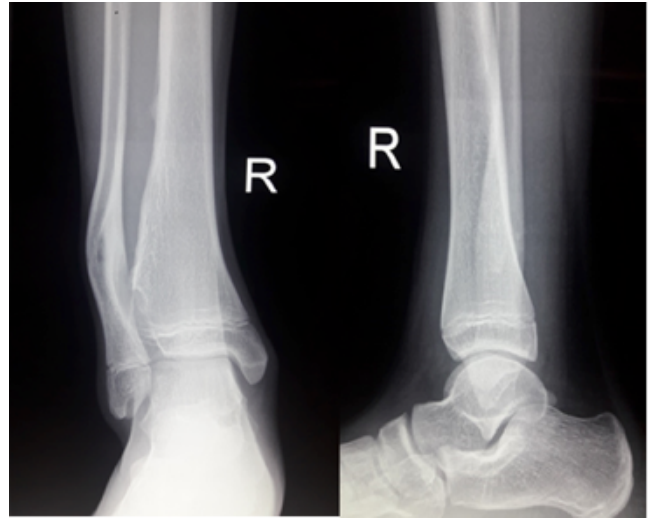

Figure 4. Post operative radiographs AP and lateral

show an abrupt increase in size or symptoms are suspect for this transformation. ${ }^{4}$

Osteochondromas arising from the distal tibia causing deformation of the fibula have been infrequently reported in literature and have usually been limited to case reports. In 1990, three cases of osteochondroma of distal tibial were reported causing impingement and deformity of the fibula. ${ }^{5}$ In 1997, one and half years old child case was reported with syndesmotic widening and ankle valgus who underwent excision at the age of two years and remained symptom free at 13 years of follow up. ${ }^{6}$ In 2000, 23 cases of distal tibial osteochondroma managed over a period of 16 years were reviewed. They concluded that untreated or partially excised lesions in skeletally immature individuals are likely to grow and may cause plastic deformation of the tibia and fibula and lead to a pronation deformity of the ankle. ${ }^{7} \mathrm{~A}$ case of osteochondroma arising from interosseous border of the distal tibia causing fibular deformity was reported in 2009. ${ }^{8}$ A similar lesion causing fibular deformity and peroneal nerve entrapment neuropathy, in $2014 .{ }^{9}$ Three cases of distal tibial osteochondromas with peroneal nerve entrapment in 2018 and suggested that such a complication is not as rare as previously thought. ${ }^{10}$

Plastic deformation of tibia and fibula, mechanical block to ankle motion, syndesmotic issues such as diastasis or synostosis, varus or valgus deformity of the ankle all leading to eventual ankle arthrosis are reported in literature. As a result, most authors recommend early excision of tumours in this location. ${ }^{6-9}$ Various approaches to the tumour have been described such as anterior, posterior and trans- 
fibular approach with fibular reconstruction. ${ }^{8}$ Most authors favor the anterior approach without fibular osteotomy. We used the anterolateral approach to the distal tibia with gratifying results.

\section{CONCLUSIONS}

This case highlights and reiterates the need for early intervention in interosseous osteochondromas which may be pedunculated or sessile. Such an approach would likely prevent the need for complex reconstructive surgery involving the syndesmosis joint or corrective osteotomies to regain a stable ankle joint, which otherwise may be required to perform due to late presentations, or the conservative management of these benign tumours.

To cite this article: Singh CM, Magar MT, Sud AD. Osteochondroma of the Distal Tibia Leading to Deformity and Stress Fracture of the Fibula - A Case Report. MJSBH. 2021;20(2):173-6.

Conflict of Interest: None declared

\section{REFERENCES}

1. Murphey MD, Choi JJ, Kransdorf MJ, Flemming DJ, Gannon FH. Imaging of osteochondroma: variants and complications with radiologic-pathologic correlation. Radiographics. 2000;20(5):1407-34. DOI: https://doi.org/ 10.1148/radiographics.20.5.g00se171407

2. Kitsoulis P, Galani V, Stefanaki K, Paraskevas G, karatzias G, Agnantis NJ et al. Osteochondromas: review of the clinical, radiological and pathological features. In Vivo. 2008;22(5):633-46. PMID:18853760

3. Felasfa M. Wodajo, MD: Top Five Lesions That Do Not Need Referral to Orthopedic Oncology - Orthop Clin N Am. 2015;46(2015):303-14. DOI:https://doi.org/10.1016/j.ocl.2014.11.012

4. Krieg JC, Buckwalter JA, Peterson KK, El-Khoury GY, Robinson RA. Extensive growth of an osteochondroma in a skeletally mature patient: A case report. JBJS. 1995;77(2):269-73. DOI:https://doi.org/ 10.2106/00004623-199502000-00015

5. Danielson LG, El-Hadad I, Quadros O. Distal tibial osteochondroma deforming the fibula. Acta Orthop Scand. 1990;61(5):469-70. DOI:https://doi.org/10.3109/17453679008993566

6. Spatz DK1, Guille JT, Kumar SJ. Distal tibiofibular diastasis secondary to osteochondroma in a child. Clin Orthop Relat Res. 1997 Dec;(345):195-7. DOI:https://doi.org/10.1097/00003086-199712000-00028

7. Chin KR, Kharazzi FD, Miller BS, Mankin HJ, Gebhardt MC. Osteochondromas of distal aspect of tibia and fibula; Natural history and treatment. J Bone Surg Am. 2000;82(9):1269-78. DOI:https://doi.org/ 10.2106/00004623-200009000-00007

8. Want IH, Sharma S, Malik FH, Sharma S, Singh M, Shekhe I. Distal tibial interosseous osteochondroma with impending fracture of fibula- a case report and review of literature. Cases J. 2009;2(1):115. DOI: https://doi.org/ 10.1186/1757-1626-2-115

9. Genc B, Solak A, Sahib A. Distal tibial osteochondroma causing fibular deformity and deep peroneal nerve entrapment neuropathy: a case report. Acta Orthop Taumatol Turc. 2014;48(4):463-6. DOI: https://doi.org/10.3944/ AOTT.2014.2741

10. Mehraj M, Shah I. Osteochondroma of distal tibia: A case series. Int J Orthop Sci. 2018;4(1):665-6. DOI: https:// doi.org/10.22271/ortho.2018.v4.i1j.96 